\title{
Física Moderna e Contemporânea no primeiro ano do Ensino Médio: Laser de Rubi um exemplo de Unidade de Ensino Potencialmente Significativa
}

Daniela Schittler daniela.schittler@iffarroupilha.edu.br 000-0002-8738-1883

Instituto Federal de Educação, Ciência e Tecnologia Farroupilha - Campus Júlio de Castilhos, Rio Grande do Sul, Brasil.

\section{Marco Antonio Moreira} moreira@if.ufrgs.br 000-0003-2989-619X

Rio Grande do Sul, Rio Grande do Sul, Brasil.

\section{RESUMO}

Este artigo relata uma experiência de ensino de tópicos de Física Moderna e Contemporânea (FMC) no 1o ano do Ensino Médio com o tema Laser de Rubi. A metodologia de pesquisa qualitativa está baseada principalmente na Teoria da Aprendizagem Significativa de Ausubel utilizando alguns vieses da Teoria de Novak, a Teoria da Educação de Gowin, Teoria dos Campos Conceituais de Vergnaud e os Modelos Mentais de Johnson-Laird. A metodologia didática usada é a Unidade de Ensino Potencialmente Significativa - UEPS, tendo o tema específico Laser de Rubi. A UEPS foi aplicada, em duas turmas do Curso Técnico em Informática Integrado em 2012, no Instituto Federal de Educação, Ciência e Tecnologia Farroupilha, Campus Júlio de Castilhos-RS. O presente artigo refere-se a continuidade do trabalho ao reaplicar a UEPS em 2013 na mesma instituição de ensino, porém tendo como público-alvo da pesquisa os alunos de três Turmas do Curso Técnico em Agropecuária Integrado.
\end{abstract}

PALAVRAS-CHAVE: Aprendizagem Significativa, Laser, Ensino de Física e Unidades de Ensino Potencialmente Significativa. 


\section{INTRODUÇÃO}

A proposta de inserção de tópicos de Física Moderna e Contemporânea (FMC) no currículo do Ensino Médio (EM) ocupa, de maneira expressiva, as pesquisas na área de Ensino de Física nos últimos trinta anos. No entanto, esta proposta apresenta três problemas principais: (1) a maioria dos professores de Física do Ensino Médio não está preparada para discutir os conceitos básicos de FMC; (2) os programas a serem cumpridos são extensos e passam a ser não compatíveis com a carga horária oferecida nas escolas públicas de Ensino Médio; e (3) a maioria dos livros didáticos quando apresenta o tema FMC, o faz de forma superficial. Em contrapartida, estudantes de pós-graduação realizam vários estudos para introduzir a FMC com novas metodologias e abordagens no EM, elaboram textos de apoio aos professores, realizam cursos de extensão para alunos de Licenciatura em Física e para professores atuantes na área como tentativa de começar uma mudança no programa da disciplina de Física no Ensino Médio.

Este trabalho procurou, inicialmente, viabilizar a compreensão de um modelo semi-clássico e de um princípio fundamental, que são o modelo do Átomo de Bohr e o princípio da Conservação do Momento Angular. Com o uso destes fundamentos físicos foram abordados o Efeito Laser e o Laser de Rubi no primeiro ano do Ensino Médio através de uma Unidade de Ensino Potencialmente Significativa (UEPS; MOREIRA, 2011).

O objetivo principal do trabalho é investigar se é possível introduzir conceitos fundamentais de Física Moderna e Contemporânea no primeiro ano do Ensino Médio e, ainda, se a metodologia da Unidade de Ensino Potencialmente Significativa é uma ferramenta eficaz para isso.

O referencial teórico está baseado principalmente na Teoria da Aprendizagem Significativa de Ausubel $(1968,2000)$. Para Ausubel, existem algumas condições necessárias para que ocorra a aprendizagem significativa: a existência de um material potencialmente significativo, isto é, um material didático capaz de facilitar a captação de significados, a disponibilidade de uma estrutura cognitiva adequada que permita a subsunção, a disposição do aluno para aprender e um professor que mostre satisfação em ensinar (SOARES, 2009). Nessa linha desenvolveu-se o conceito de Unidades de Ensino Potencialmente Significativas (MOREIRA, 2011) baseadas na teoria da Aprendizagem de David Ausubel $(1968,2000)$, em visões clássicas e contemporâneas (MOREIRA, 2006; MASINI e MOREIRA, 2008; VALADARES e MOREIRA, 2009), nas teorias de educação de J.D. Novak (2000) e de D.B. Gowin (1981); na teoria dos campos conceituais de Gérard Vergnaud (1990; MOREIRA, 2004) e na teoria dos modelos mentais de Johnson-Laird (1983; MOREIRA, 2010).

O artigo está estruturado de forma a conteplar: o contexto em que a pesquisa foi aplicada; a metodologia de pesquisa; a metodologia didática; a analise de dados e resultados, descrição do perfil das turmas e os resultados obtidos com a aplicação da UEPS Laser de Rubi; considerações finais; e as referências.

\section{Contexto}


Em 2012, a UEPS, com o tema Laser de Rubi, foi aplicada, como estudo-piloto (SCHITTLER e MOREIRA, 2014), em duas turmas do Curso Técnico em Informática Integrado do Instituto Federal de Educação, Ciência e Tecnologia Farroupilha Campus Júlio de Castilhos. No ano de 2013, a UEPS Laser de Rubi foi reaplicada em três turmas do Curso Técnico em Agropecuária Integrado desta mesma instituição. As turmas do Curso Técnico em Agropecuária Integrado são denominadas, Agro1A, Agro-1B e Agro-1C tendo, 21, 21 e 22 alunos, respectivamente. As três turmas foram divididas em 12 grupos identificados por cores: 1) Agro-1A: Grupo Amarelo, Grupo Laranja, Grupo Verde e Grupo Vermelho; 2) Agro-1B: Grupo Laranja, Grupo Marrom, Grupo Verde e Grupo Vermelho; e 3) Agro-1C: Grupo Amarelo, Grupo Marrom, Grupo Preto e Grupo Vermelho.

\section{Metodologia de Pesquisa}

O presente trabalho é considerado uma Pesquisa Qualitativa, tendo em vista suas características principais. A característica interpretativa da pesquisa qualitativa refere-se à capacidade do ser humano de criar interpretações significativas da parte física e do comportamento. De modo geral, o interesse central da pesquisa está na questão dos significados que as pessoas atribuem a eventos e objetos, em suas ações e interpretações dentro de um contexto social e na exposição desses significados pelo pesquisador. A pesquisa qualitativa pode ser caracterizada como a tentativa de uma compreensão detalhada dos significados e características situacionais apresentadas pela pesquisa, em lugar da produção de medidas quantitativas de características de comportamento. O pesquisador observa participativamente inserido no meio estudado, imerso no fenômeno e atento aos pormenores. Ao realizar-se uma pesquisa qualitativa constroem-se suposições na tentativa de explicar o que se desconhece. Esta suposição tem por característica ser provisória, podendo ser testada ou não. Coerentemente a pesquisa qualitativa não possui a pretensão de generalizar dados, ou melhor, os resultados obtidos com a pesquisa não podem ser usados como um padrão ou uma possibilidade de transferência dos resultados encontrados para outros contextos. A principal preocupação da pesquisa qualitativa esta na particularização e não na generalização. Portanto, utilizou-se a pesquisa qualitativa de modo geral considerando suas características principais, que são: interpretativa, detalhada, que constrói suposições e não visa generalizações.

\section{Metodologia Didática}

A metodologia didática aplicada neste trabalho é o modelo de Unidades de Ensino Potencialmente Significativas (UEPS). A UEPS construída contempla os conteúdos: Princípio da Conservação do Momento Angular, Modelo do Átomo de Bohr, Quantização da Energia, Diagrama de Níveis de Energia para o átomo de hidrogênio, Inversão de População, efeito Laser e Laser de Rubi. Esta UEPS construída com o tema Laser possui os seguintes passos:

1) Tarefa inicial: os grupos são incentivados a elaborar um Mapa Livre com o uso de fichas com as palavras - Física - Princípio da Conservação do Momento Angular - Quantização de Energia - Modelo do Átomo de Bohr - Inversão de 
explicações para não interferir nas explicações do próximo grupo. A atividade envolve duas horas/aula.

II) Situações-problema iniciais: II.1) Os alunos respondem em seus grupos um questionário e após discutem com o grande grupo: (a) O que você já leu, ouviu, ou viu sobre Laser? (b) Esta aplicação da Física envolve a Física Clássica ou a Física Moderna? (c) Qual das Físicas citadas na pergunta anterior você estuda no Ensino Médio? (d) Qual das Físicas citadas na pergunta anterior você percebe implicações na sua vida? (e) Dê alguns exemplos de implicações da Física no seu dia-a-dia. II.2) Leitura coletiva do texto Os Fundamentos da Luz Laser, publicado na Revista Física na Escola, volume 2, número 2, ano 2001 [17]. Nessa atividade os grupos destacam as palavras do texto não compreendidas. A atividade envolve três horas/aula.

III) Aprofundando conhecimentos: III.1) Com os dados coletados nas atividades do mapa livre, nas respostas do questionário e nas palavras destacadas durante a leitura coletiva do texto, os conceitos propostos na UEPS são trabalhados de forma ordenada e sistemática, através de filmes, slides, material disponível na internet, texto de apoio do Grupo de Ensino da Física - GEF da Universidade Federal de Santa Maria - UFSM e aulas expositivas e dialogadas, sendo os alunos sempre estimulados a participar de todas as discussões. III.2) Os grupos retomam o texto Os Fundamentos da Luz Laser e, constroem um esquema ou um resumo para melhor entendê-lo. A etapa III prevê 6 horas/aula.

IV) Nova Situação-Problema: IV.1) Os alunos em grupo pesquisam uma aplicação do Laser e apresentam aos colegas. A pesquisa será realizada como tarefa de casa e a apresentação envolve uma hora/aula. IV.2) Os grupos constroem um mapa conceitual com os conceitos envolvidos na UEPS. Esta atividade envolve 3 horas/aula.

V) Avaliação somativa individual: os alunos são avisados com antecedência e lhes serão propostas as seguintes questões abertas: 1. No texto, Os Fundamentos da Luz Laser, publicado na Revista Física na Escola, volume 2, número 2, ano 2001, encontramos a seguinte frase: "Funcionando como fonte de luz de características únicas, o laser possui propriedades especiais que o tornam um excelente instrumento de uso científico e tecnológico." Quais são estas propriedades especiais que o texto se refere. 2 . De forma sucinta descreva como se forma a Luz Laser. 3. Justifique o nome Laser de Rubi. 4. Com base nos trabalhos apresentados sobre as aplicações da luz laser, descreva o seu. 5. Avalie a sua aprendizagem e as aulas de Física desde a construção do mapa livre. A atividade é desenvolvida em uma hora/aula.

VI) Aula expositiva dialogada integradora final: a professora juntamente com os alunos retoma os conceitos através de um mapa conceitual. Salientando a importância do Laser, sua utilização, seus benefícios e seus malefícios, recordando as explicações de cada grupo. Essa atividade necessita 1 hora/aula.

VII) Avaliação da aprendizagem da UEPS: A avaliação é baseada nas atividades realizadas: na comparação entre o mapa livre e o mapa conceitual, na apresentação de uma aplicação do Laser, no material confeccionado para a apresentação e na avaliação somativa individual.

VIII) Avaliação da própria UEPS: a professora avalia a forma em que foi abordado o tema Laser de Rubi em função de seus resultados e da avaliação dos 
alunos, se necessário serão reformuladas em implemantações futuras. As atividades desenvolvidas na UEPS contemplam o total de dezesseis horas/aula.

\section{Análise de Dados e Resultados}

A análise de dados e resultados estrutura-se com a descrição do perfil das turmas envolvidas na pesquisa e a apresentação dos resultados obtidos com a aplicação da UEPS Laser de Rubi.

\section{Perfil das Turmas}

As turmas Agro-1A, Agro-1B e Agro-1C tinham algumas peculiaridades. A turma Agro-1A foi considerada uma turma atípica por iniciar o ano letivo com 26 alunos, sendo 19 meninos e 7 meninas. Nessa turma houve discriminação de gênero e foi detectado bulling por parte de alguns meninos. Do total de 26 alunos, dois nunca compareceram, um transferido do Instituto Federal Farroupilha do Campus de São Vicente do Sul e após problemas disciplinares transferiu-se do Campus Júlio de Castilhos para uma escola de Ensino Médio, uma aluna desistiu no segundo bimestre por não resistir ao bulling e, um aluno desistiu no quarto bimestre por falta de interesse e se considerar reprovado. A turma dividiu-se em dois grupos de alunos: um grupo com facilidade e o outro com dificuldade na aprendizagem. Assim, do total de 26 alunos matriculados na turma Agro-1A, 21 frequentaram as aulas até o final do ano letivo. A turma Agro-1B iniciou com 26 alunos, um nunca compareceu e quatro desistiram por falta de interesse e considerar que estavam reprovados, assim, no término do ano letivo totalizaram 21 alunos. A turma é considerada muito participativa e por isso, conseguiu superar as dificuldades de aprendizagem. A turma Agro-1C inicia o ano letivo com 25 alunos, sendo que um aluno nunca compareceu e dois desistiram no quarto bimestre por se considerarem reprovados, assim concluiu-se o ano letivo com 22 alunos. A turma Agro-1C é a turma que possuía o maior número de alunos com dificuldades de aprendizagem, porém a maioria dos alunos se identificava com o perfil do Curso Técnico em Agropecuária.

\section{Resultados}

A análise dos resultados obtidos na pesquisa obedece a sequência adotada pela UEPS apresentada na Metodologia Didática. Na etapa I da UEPS os alunos em grupo construíram um mapa livre e filmaram suas explicações. Com essa atividade detectou-se conhecimentos prévios dos grupos. Durante a realização da atividade percebeu-se as mesmas dificuldades encontradas pelas turmas do projeto-piloto em 2012 (Schittler e Moreira, 2014). No entanto, a pesquisadora no início da atividade enfatizou que o mapa livre não seria avaliado no sentido, de certo ou errado, mas sim em relação ao envolvimento e participação. A atividade de construção dos mapas livres e a filmagem das explicações foi proposta e realizada em duas horas/aula nas turmas Agro-1A, Agro-1B e Agro-1C.

Assim como no estudo-piloto a filmagem foi uma ferramenta eficaz utilizada 
que a Física é ligada com todas as fichas por isso desenhamos várias flechas que saem desta ficha. A ideia do Modelo atômico de Bohr foi responsável por várias inovações e a quantização de energia, canetas e as demais fichas......, sendo o Princípio da Conservação do Momento Angular ligado a Quantização da Energia e a Inversão da População ligada ao Diagrama de Energia”; (2) Grupo Laranja - “ ...o nosso mapa iniciou com a Física por ser a ficha mais importante, sendo que o Modelo do Átomo de Bohr explica a formação do Laser de Rubi que é uma Inovação e possui muitas aplicações como as cirurgias e canetas, da mesma forma que é explicado pelo Diagrama de Energia, Inversão da População..."; (3) Grupo Amarelo - " ... o nosso mapa começa com a palavra Física por que é o conceito mais importante, este foi divido em duas partes.... o mapa possui algumas palavras que não sabemos o significado, como é o caso de Inversão de População..."; e (4) Grupo Vermelho - " ... a Física está ligada diretamente com as Inovações, Diagramas de Energia e Quantização de energia. As Inovações podem ser explicadas com o Modelo do Átomo de Bohr, que explica o Laser e Laser de Rubi que são usados em Cirurgias... As inovações também podem ser explicadas com as Canetas, o Princípio da Conservação do Momento Angular e a Inversão de População...".

Em continuidade, destacam-se as transcrições relevantes de cada grupo da turma Agro-1B: (1) Grupo Verde - “ ... dentro das inovações tem as cirurgias que ajudaram na retirada de tumores e as canetas que possibilitaram a escrita com tinta, depois vem as cirurgias que são a laser que são inovações e as canetas a laser ... no laser tem a questão do laser de rubi que foi usado na física para fazer a experiência do átomo de Bohr... dentro do átomo de Bohr tem o Princípio da Conservação do Momento Angular que é ligado com diagramas de energia, inversão de população e quantização a energia". (2) Grupo Laranja - "...nós entendemos que a Física é o começo de tudo e que o Princípio da Conservação do Momento Angular pode ser entendido com o Modelo Atômico de Bohr ... que é circular ...A Inversão de População tem a ver com o Modelo Atômico de Bohr por que os elétrons giram em torno do átomo pela quantização de energia e pela quantização de energia tem-se o diagrama de energia. Para se ter o diagrama de energia precisa-se ter a quantização de energia. $E$ as inovações são exemplos de canetas à laser, que contribuíram para o desenvolvimento do laser de rubi." ; (3) Grupo Marrom - "Física, Princípio da conservação do Momento Angular, Quantização da Energia, Inversão de População, Diagramas de Energia tudo isso explica o Modelo Atômico de Bohr que gera inovações que são as canetas a laser e o laser de rubi que é utilizado nas cirurgias" ; e (4) Grupo Vermelho - "...a física nos ensina o princípio da conservação do momento angular no modelo do átomo de Bohr, quantização de energia e diagrama de energia e isso resultou em algumas inovações. Falando em inovação podemos pensar em tecnologia, a inversão de população, a cirurgia, o laser, as canetas e o laser de rubi".

Destacam-se, a seguir, as transcrições relevantes de cada grupo da turma Agro-1C: (1) Grupo Preto - "... a Física envolve tudo o que temos no papel, o Princípio da Conservação da Energia é o que produz o diagrama de energia. No diagrama de energia é onde mostra se perdeu ou ganhou energia no modelo do átomo de Bohr. Tem a situação do elétron no átomo que mostra a inversão de população. O modelo do átomo de Bohr é uma inovação que torna possível as cirurgias a laser, que são feitas por laser de rubi,e tem que ser de rubi por que tem que ser da cor vermelha; (2) Grupo Amarelo - “... a Física está em cima por que engloba todos os componentes das fichas, o Princípio da Conservação do 
Momento Angular se liga ao Modelo Atômico de Bohr, e a quantização da energia se liga ao Modelo Atômico de Bohr por que Bohr diz que em seu modelo as energias são quantizadas, no Diagrama de energia apresenta a Inversão de População dos elétrons e dos prótons do átomo. As Inovações são as cirurgias feitas com laser e feitas com Canetas com Laser de Rubi"; (3) Grupo Marrom - "... a Física explica o Princípio da Conservação do Momento Angular, que forma o Modelo do Átomo de Bohr transformado em Diagramas de Energia dando origem ao Laser de Rubi que é a Quantização de energia formando canetas e laser proporcionando inversão de população nas inovações das cirurgias"; e (4) Grupo Vermelho - "... a Física engloba todos os temas, iniciamos com o Modelo do Átomo de Bohr que acho que tem relação com o Princípio da Conservação do Momento Angular, que está ligada com o Diagrama de Energia e a Quantização da Energia e que dá uma Inversão de População. As Inovações tem ligação com as Cirurgias que são feitas com as Canetas a Laser que são os Laser de Rubi". 
Figura 1 - Exemplos de Mapas Livres: (a) Grupo Verde; (b) Grupo Laranja; (c) Grupo Amarelo; e, (d) Grupo Vermelho.

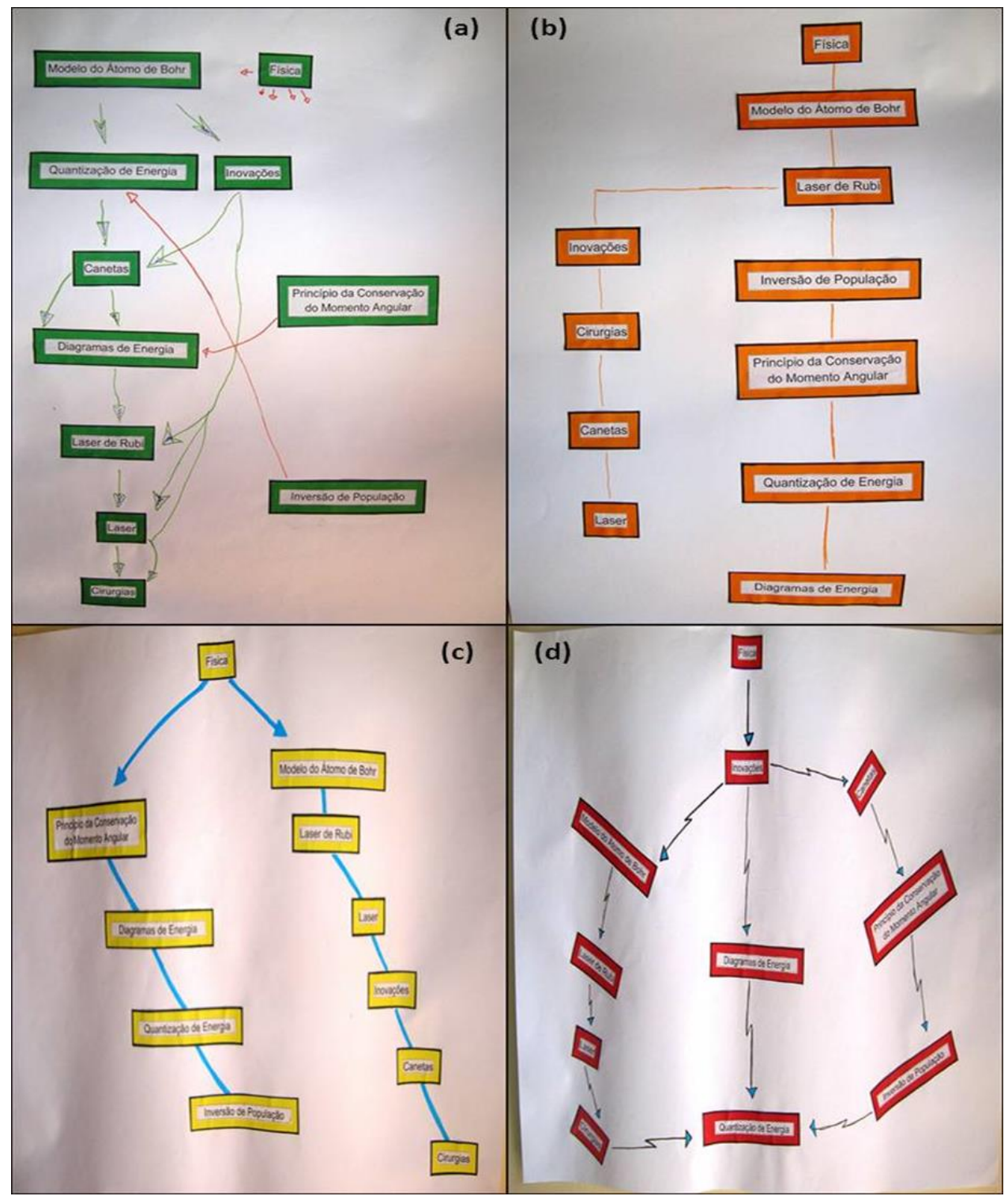

Na etapa II.1 da UEPS os grupos responderam ao questionário. Com base em seus conhecimentos responda: (a) O que você já leu, ouviu, ou viu sobre laser? (b) Esta aplicação da física envolve a Física Clássica ou a Física Moderna? (c) Qual das Físicas citadas na pergunta anterior você estuda no Ensino Médio? (d) Qual das Físicas citadas na pergunta anterior você percebe implicações na sua vida? (e) Dê alguns exemplos de implicações físicas do seu dia-a-dia.

As respostas da turma Agro-1A evidenciaram: na questão (a) um conhecimento vago sobre o tema laser; na (b) apenas o grupo laranja identificou o laser como parte da Física Clássica; na (c) em relação a Física estudada no Ensino Médio, os grupos laranja e vermelho identificaram a Física Moderna e os grupos verde e amarelo identificaram ambas; na (d) a Física que os alunos perceberam no dia-a-dia é a Física Clássica para os grupos amarelo e vermelho, a FC e FM para o grupo verde e apenas a FM para o grupo laranja; e na questão (e) os grupos 
amarelo e vermelho exemplificaram com conteúdos estudados até o momento nas aulas de física, com isso, os grupos são coerentes com a resposta da questão (d), da mesma forma que os grupos verde e laranja.

As respostas obtidas na turma Agro-1B: na questão (a) todos os grupos evidenciaram o uso do laser na área médica; na (b) todos os grupos afirmaram que o laser envolve conhecimentos de Física Moderna; na (c) três grupos responderam que no Ensino Médio são estudadas ambas as Físicas e apenas o grupo verde respondeu que é a Física Clássica; na (d) o grupo verde e o laranja perceberam aplicações da Física Clássica no seu dia-a-dia, o grupo marrom considerou ambas, e o grupo vermelho a Física Moderna; e na questão (e) três grupos exemplificaram as implicações do dia-a-dia com os conteúdos trabalhados até o momento e, apenas o grupo vermelho exemplificou a FM com chuveiro, luz, raio e carro.

As respostas da turma Agro-1C evidenciaram: que na questão (a) os grupos preto e marrom usaram o aparelho de celular para obter informações, o grupo amarelo relacionou a palavra laser a alguns fenômenos apresentados em filmes de ficção científica, além de características fundamentais, o grupo vermelho citou os conceitos apresentados nas fichas recebidas para a construção do mapa livre; na (b) todos os grupos relacionaram o laser a Física Moderna; (c) três grupos afirmaram que estudaram no Ensino Médio ambas as Físicas e, apenas o grupo vermelho citou estudar apenas a Física Clássica; (d) dois grupos perceberam no dia-a-dia implicações da Física Clássica, um a Física Moderna e outro grupo ambas as físicas; e na questão (e) os grupos que citaram a FC na questão (d) exemplificaram com conteúdos trabalhados até o momento, o grupo que respondeu FM na questão (d) deu exemplos coerentes, e o grupo que respondeu ambas exemplificou com situações que abrangem conhecimentos de Física Clássica.

Pode-se concluir com as respostas iniciais dos doze grupos das turmas Agro1A, Agro-1B e Agro-1C: o conhecimento sobre o efeito laser é um conhecimento vago que não corresponde a explicação aceita pela comunidade científica no momento; onze grupos identificaram que o laser envolve conhecimentos de Física Moderna; 8 grupos afirmaram estudar no Ensino Médio tanto a Física Clássica quanto a Física Moderna, 2 grupos afirmaram ser a Física Moderna e 2 afirmaram ser a Física Clássica; 6 grupos perceberam a Física Clássica no seu dia-a-dia, 3 perceberam a Física Moderna e 3 a Física Clássica; 7 grupos apresentaram exemplos de Física Clássica, 2 apresentaram exemplos de Física Moderna e três de ambas as físicas; 10 grupos apresentaram implicações do dia-a-dia correspondente a resposta da questão (d) e apenas 2 grupos não corresponderam seus exemplos à física apresentada na questão (d).

Na etapa II.2 da UEPS, os alunos realizaram a leitura do texto e destacaram as palavras que não compreenderam o significado. Destacam-se as palavras citadas pela maioria dos grupos da Turma Agro-1A são: monocromaticidade e cátodo/anodo (para os 4 grupos), atomística/colapsaria/espiral, ampola de $\mathrm{H}$ /espectro, absorção de fóton/fóton (para três grupos). As palavras destacadas pela Turma Agro-1B são: anteparo/cavidade ressonante, elétrons do cátodo/ anodo, atomística/colapsaria/espiral, ampola de $\mathrm{H} /$ espectro (todos os grupos) e monocromaticidade e absorção de fóton/fóton (três grupos). E a Turma Agro-1C destacou as palavras: anteparo/cavidade ressonante, elétrons do cátodo/anodo, monocromaticidade e ampola de $\mathrm{H}$ /espectro (três grupos). $\mathrm{O}$ levantamento das palavras que não faziam parte do vocabulário dos alunos evidenciou o 
conhecimento vago sobre o assunto laser, como por exemplo, as palavras monocromaticidade e anteparo. Assim, detectou-se o nível de conhecimento e o distanciamento entre textos de divulgação científica e o vocabulário dos alunos envolvidos neste trabalho.

Com a tarefa inicial e as situações-problema iniciais pode-se realizar o levantamento de conhecimentos prévios dos alunos e a partir destes, iniciou-se o aprofundamento dos conhecimentos (etapa III.1). Por meio dos subsunçores coletados envolveram-se os alunos na formalização do conhecimento. A etapa III.1 foi composta de 9 horas/aula envolvendo os conteúdos da UEPS. Para obter maior compreensão do texto utilizado na etapa II.2, os alunos retomaram sua leitura (etapa III.2) e construíram um esquema ou resumo. Nos resumos percebeu-se que os alunos de todas as turmas do Curso Técnico em Agropecuária destacaram as palavras recebidas para a construção dos mapas livres e as palavras mencionadas na etapa II.2. Pode-se inferir que mesmo as palavras que não teriam significados para os alunos num primeiro momento, após a etapa III.1 tornaram-se mais significativas de tal maneira que todos os alunos as destacaram em seus resumos ou esquemas. Esta pode ser uma evidência de aprendizagem significativa.

A quarta etapa da UEPS apresentou duas atividades. Na etapa IV, os grupos deveriam pesquisar e apresentar à turma uma aplicação do laser. Com essa atividade obteve-se os temas: fisioterapia com o uso do laser, aplicações diversas do laser, cirurgia ocular a laser, diversidade nas aplicações laser, utilização do laser por militares, medicina do laser, aplicações do laser na oftalmologia, tratamento de varizes, aplicações do laser na saúde, aplicações do laser na medicina, laser na medicina - oftalmologia e aplicações policiais e na medicina do laser. Com os dados pode-se afirmar que dos doze trabalhos apresentados, apenas um, do grupo laranja da turma Agro-1B, não apresenta aplicações do laser na medicina. Os grupos durante a apresentação relataram acontecimentos de familiares ou conhecidos que sofreram algum tipo de intervenção com o uso do laser, ou seja, para os alunos o trabalho tornou-se relevante por partir de sua realidade. $\mathrm{Na}$ segunda atividade da quarta etapa da UEPS os grupos reconstruíram os mapas livres com a orientação que se tornassem mapas conceituais, exemplificam-se os mesmos na Figura 2. 
Figura 2. Exemplos de Mapas Conceituais: (a) Grupo Verde; (b) Grupo Laranja; (c) Grupo Amarelo; e, (d) Grupo Vermelho

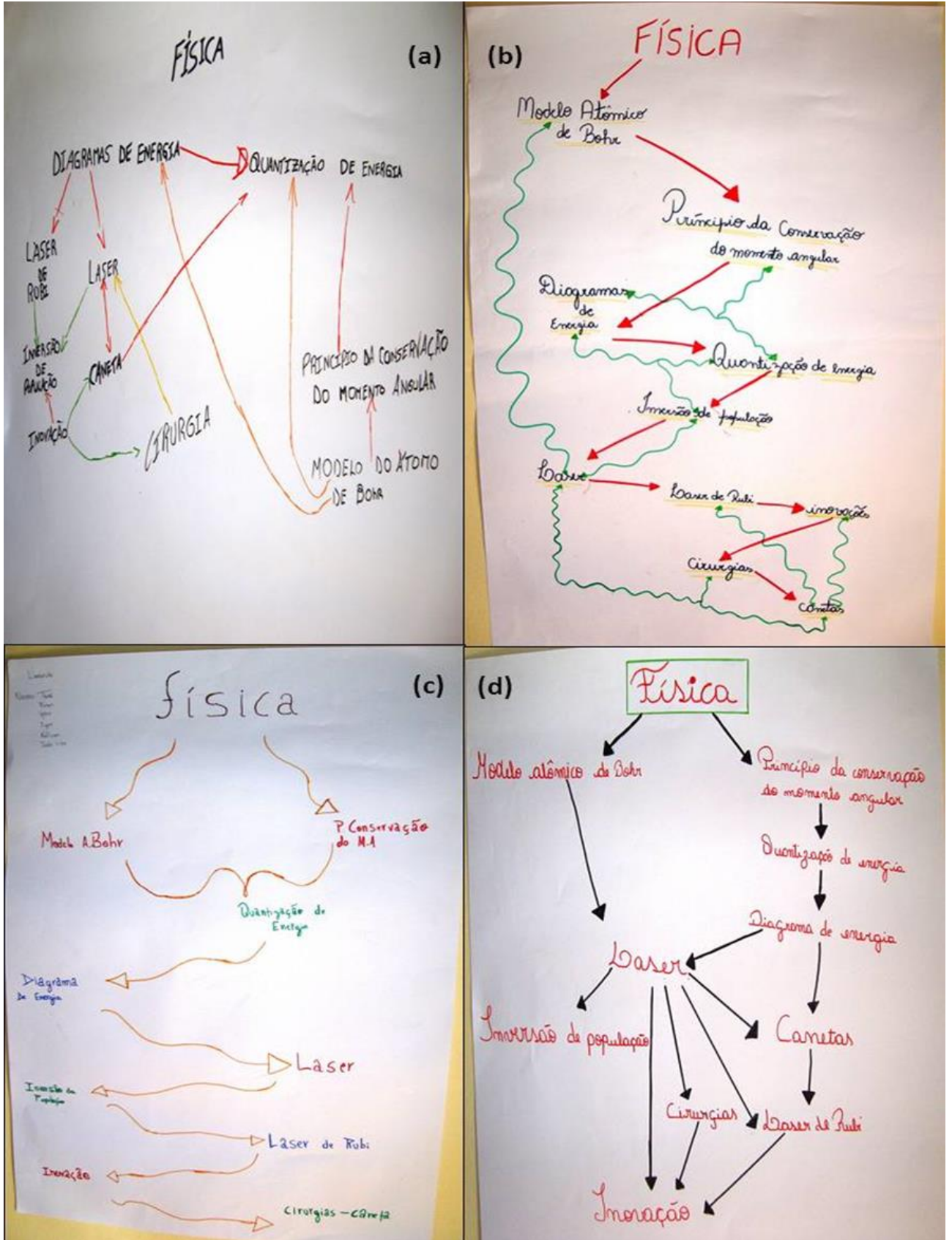

A tabela 1 contém a análise entre o mapa livre e o mapa conceitual dos exemplos das Figuras 1 e 2,na perspectiva dos pesquisadores. 
Tabela 1. Relação dos aspectos positivos e negativos entre o mapa livre e o mapa conceitual exemplificados na perspectiva dos pesquisadores.

\begin{tabular}{|c|c|c|}
\hline Grupo & Pontos Positivos & Pontos Negativos \\
\hline Verde & $\begin{array}{l}\text { A representação de várias setas no } \\
\text { conceito de Física no mapa livre } \\
\text { evidencia que o grupo entendeu que } \\
\text { a Física engloba todos os conceitos } \\
\text { apresentados. } \\
\text { O mapa livre apresentou ligações } \\
\text { entre as fichas com mais de uma } \\
\text { flecha. } \\
\text { O mapa livre apresentou um maior } \\
\text { número de ligações do que no mapa } \\
\text { livre. }\end{array}$ & $\begin{array}{l}\text { O grupo não acrescentou nenhum } \\
\text { conceito no mapa conceitual. } \\
\text { Tanto o mapa livre quanto o mapa } \\
\text { conceitual não apresentaram conectores. }\end{array}$ \\
\hline Laranja & $\begin{array}{l}\text { A explicação do mapa conceitual } \\
\text { demonstrou que o grupo colocou } \\
\text { conceitos mais abrangentes no topo } \\
\text { do mapa e os menos abrangentes na } \\
\text { base. } \\
\text { Mesmo o mapa conceitual tendo a } \\
\text { representação em linha, durante a } \\
\text { explicação os alunos esclareceram os } \\
\text { conceitos utilizando os demais } \\
\text { conceitos. }\end{array}$ & $\begin{array}{l}\text { O mapa livre evidenciou a separação entre } \\
\text { os conceitos da Física e suas aplicações. Os } \\
\text { alunos não perceberam ligações entre a } \\
\text { Física e seu dia-a-dia. } \\
\text { O grupo não acrescentou nenhum } \\
\text { conceito ao mapa conceitual. } \\
\text { Tanto o mapa livre quanto o mapa } \\
\text { conceitual não apresentaram conectores. }\end{array}$ \\
\hline Amarelo & $\begin{array}{l}\text { O mapa conceitual apresentou um } \\
\text { maior número de ligações entre os } \\
\text { conceitos; } \\
\text { A explicação evidenciou que os } \\
\text { alunos sabiam os significados de } \\
\text { cada conceito. }\end{array}$ & $\begin{array}{l}\text { O mapa livre foi dividido em duas partes: } \\
\text { a parte de conteúdos de Física e os } \\
\text { exemplos do dia-a-dia. } \\
\text { O grupo apresentou as mesmas palavras } \\
\text { no mapa livre e conceitual. } \\
\text { Tanto o mapa livre quanto o mapa } \\
\text { conceitual não apresentaram conectores. }\end{array}$ \\
\hline Vermelho & $\begin{array}{l}\text { Os mapas evidenciaram a maior } \\
\text { compreensão por parte dos alunos, } \\
\text { maior relação entre os conceitos. }\end{array}$ & $\begin{array}{l}\text { Tanto o mapa livre quanto o mapa } \\
\text { conceitual não apresentaram conectores } \\
\text { e não foi acrescentado nenhum conceito. }\end{array}$ \\
\hline
\end{tabular}


As atividades de construção do mapa livre e conceitual nas turmas Agro-1A, Agro-1B e Agro-1C evidenciaram que os grupos: (1) na maioria dos mapas livres foi representado a separação entre os conteúdos de Física e as aplicações; (2) todos os grupos não acrescentaram conceitos quando construíram o mapa conceitual; (3) nenhum grupo apresentou conectores no mapa conceitual; e (4) todos os grupos ao explicar seus mapas conceituais apresentaram explicações que evidenciaram a compreensão do conteúdo e o crescimento individual do grupo.

Considera-se que a estrutura cognitiva do aprendiz é única e por isso todos os significados adquiridos, embora compartilhados, também terão aspectos únicos. Assim, pensando na unicidade de cada aprendiz foi proposta uma avaliação somativa individual, denominada etapa $V$ da UEPS. A seguir, analisam-se as respostas obtidas. Na Questão 1: 1. No texto, Os Fundamentos da Luz Laser, publicado na Revista Física na Escola, volume 2, número 2, ano 2001, encontra-se a seguinte frase: "Funcionando como fonte de luz de características únicas, o laser possui propriedades especiais que o tornam um excelente instrumento de uso científico e tecnológico." Quais são estas propriedades especiais que o texto se refere. A resposta da questão 1 é considerada correta quando o aluno cita as 4 características da luz laser - monocromaticidade, coerência, direcional e alta intensidade, a questão é considerada $1 / 2$ correta quando o aluno cita duas características, 3/4 correta quando o aluno apresenta 3 características, 1/4 quando apresenta apenas uma e a questão é considerada errada quando o aluno não apresenta nenhuma das características da luz laser. Atenta-se que, para a questão 1 da avaliação somativa individual foi considerada: correta para 47 alunos, parcialmente correta $3 / 4$ para 14 alunos, parcialmente correta $1 / 2$ para 20 alunos, parcialmente correta $1 / 4$ para 5 alunos, incorreta para 25 alunos e 3 alunos não responderam a questão.

A questão 2, de forma sucinta descreva como se forma a Luz Laser. Com as respostas da questão 2 , verificou-se que do total de 58 respostas apenas 5 alunos responderam corretamente a questão 2, 22 respostas são parcialmente corretas , 25 respostas são consideradas incorretas, sendo que, os três alunos do Grupo vermelho da turma Agro-1A responderam incorretamente a questão, o Grupo Amarelo e o Grupo Laranja das turmas Agro-1A e Agro-1B, tinham o maior número de integrantes (dois) que responderam a questão corretamente. Apenas três alunos não responderam a questão. Exemplificam-se no quadro 1 as respostas consideradas: (a) correta, (b) parcialmente correta e, (c) incorreta.

A questão 3, Justifique o nome Laser de Rubi. As respostas obtidas para a questão 3 foram consideradas: 22 respostas corretas, 14 respostas parcialmente corretas, 18 respostas consideradas incorretas, e apenas 3 alunos não responderam a questão. Exemplificam-se no quadro 2 as respostas consideradas: (a) correta, (b) parcialmente correta e, (c) incorreta. 


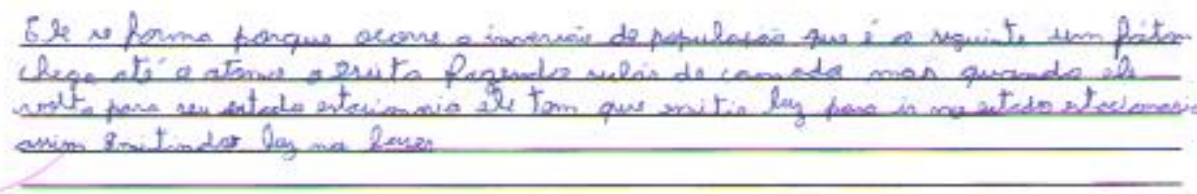

Ele se forma porque ocorre a inversão de população que é o seguinte, um fóton chega até o átomo aumentando, fazendo subir de camada mas quando ele volta para o estado estacionário ele emite luz para voltar ao estacionário, assim emitindo luz laser. Resposta parcialmente correta.

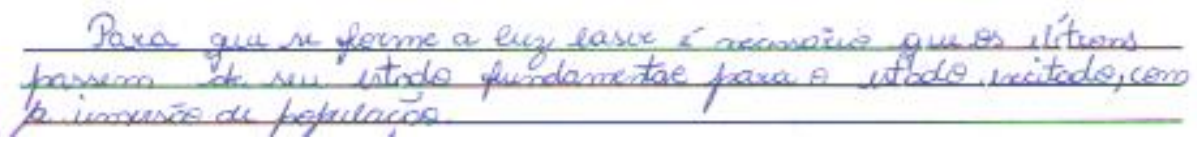

Para que se forme a luz laser é necessário que os elétrons passem de seu estado fundamental para o estado excitado, com a inversão de população. Resposta incorreta.

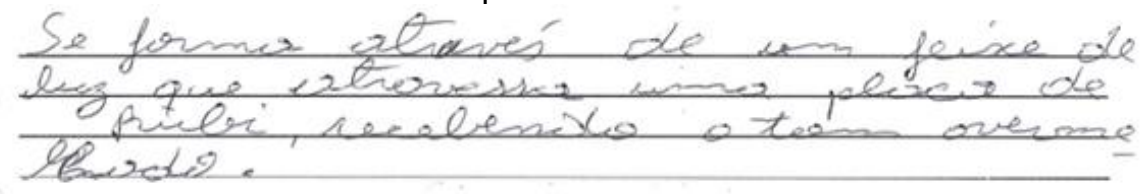

Se forma através de um feixe de luz que atravessa uma placa de Rubi, recebendo o tom avermelhado.

Quadro 2. Respostas da questão 3 consideradas: (a) correta, (b) parcialmente correta, e (c) incorreta.

Resposta correta.

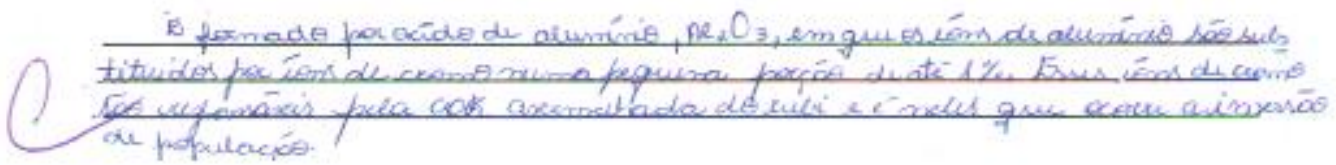

É formado por óxido de alumínio, $\mathrm{Al}_{2} \mathrm{O}_{3}$, em que íons de alumínio são substituídos por íons de cromo numa pequena porção de até 1\%. Esses íons de cromo são responsáveis pela cor avermelhada do rubi e é neles que ocorre a inversão de população.

Resposta parcialmente correta.

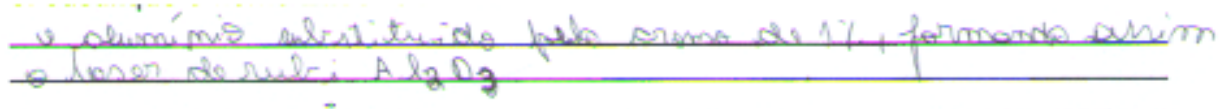

O alumínio substituído pelo cromo de 1\%, formando assim, o laser de rubi, $\mathrm{Al}_{2} \mathrm{O}_{3}$. Resposta incorreta.

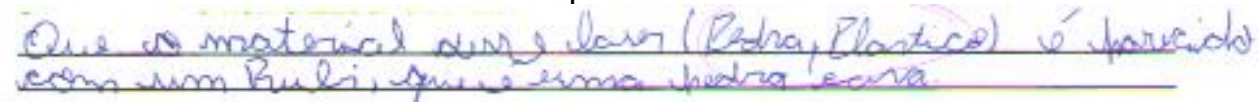

Que o material desse laser (Pedra, Plástico) é parecido com um Rubi, que é uma pedra rara. 
A questão 4, com base nos trabalhos apresentados sobre as aplicações da luz laser, descreva o seu trabalho." A resposta é considerada correta, quando o aluno descreve o seu trabalho, a resposta é considerada parcialmente correta quando o aluno apenas cita o trabalho apresentado, e, a resposta é considerada incorreta se o aluno apresenta o trabalho de outro grupo. Considerou-se 42 respostas corretas, como por exemplo, "Meu trabalho foi feito sobre oftalmologia, falava sobre como o laser ajudou muito nesta área substituindo os bisturis e fazendo com que as cirurgias fossem indolores"; 11 respostas consideradas parcialmente corretas, por exemplo, "depilações a laser"; e, apenas 1 aluno do Grupo Marrom da Turma Agro1B respondeu incorretamente a questão 4. Observa-se que todos os alunos responderam a questão. Com esta atividade pode-se detectar que os alunos participaram de maneira ativa na pesquisa da aplicação da luz laser.

A questão 5, Avalie a sua aprendizagem e as aulas de Física desde a construção do mapa livre. Apresentam-se na tabela 4 as descrições da avaliação dos alunos por grupo e turma sobre sua aprendizagem e o método aplicado pela pesquisadora.

Tabela 4. Respostas da questão 5.

\begin{tabular}{|c|c|}
\hline Turma & Descrições \\
\hline \multirow[t]{4}{*}{ Agro-1A } & $\begin{array}{l}\text { Achei mais interessante trabalhar desta forma, porque assim a gente é } \\
\text { mais livre para pensar e não tem o peso por fazer uma coisa e estar errado, } \\
\text { resultando num melhor aprendizado. }\end{array}$ \\
\hline & $\begin{array}{l}\text {...foi possível interagir com os colegas... } \\
\text {...pude tentar entender sobre o assunto sem a professora explicar, e } \\
\text { depois a professora explicou e então tive outra visão do assunto... }\end{array}$ \\
\hline & $\begin{array}{l}\text {...os conceitos não faziam sentido, mas agora não... } \\
\text {...o mapa livre ajudou a entender os conceitos e organizá-los... o trabalho } \\
\text { em grupo ajudou a tirar as nossas dúvidas ali.. }\end{array}$ \\
\hline & $\begin{array}{l}\text {...acho que desta maneira a gente aprende mais... } \\
\text {... quando eu fiz o mapa livre eu não entendi mas quando a professora } \\
\text { explicou os detalhes separados eu entendi melhor }\end{array}$ \\
\hline \multirow[t]{3}{*}{ Agro-1B } & $\begin{array}{l}\text {... a construção dos mapas foi uma atividade que nos estimulou a } \\
\text { raciocinar e construí-lo a partir do que nós sabíamos... }\end{array}$ \\
\hline & $\begin{array}{l}\text {... as aulas tiveram um ar de descontração e interesse que despertava } \\
\text { mais curiosidade sobre o assunto... }\end{array}$ \\
\hline & $\begin{array}{l}\text {... o método deixa expressar o que vimos e entendemos das aulas de } \\
\text { Física, no dia da construção do mapa foi muito complicado mas no decorrer do } \\
\text { trabalho fui entendo ... }\end{array}$ \\
\hline
\end{tabular}




\begin{tabular}{|c|c|}
\hline \multirow[t]{2}{*}{ Agro-1B } & $\begin{array}{l}\text {...foi melhor aprender assim pois sozinhos, raciocinamos mais e } \\
\text { aprendemos mais do que só a professora explicando... }\end{array}$ \\
\hline & $\begin{array}{l}\text {... achei interessante que as aulas de Física forma mais diversificadas, } \\
\text { onde a professora buscou várias alternativas para facilitar a aprendizagem. }\end{array}$ \\
\hline \multirow[t]{3}{*}{ Agro-1C } & $\begin{array}{l}\text { Antes do mapa livre as aulas vinham bem cansativas, mas depois ficaram } \\
\text { diferentes... } \\
\text {... As aulas foram cansativas, a aprendizagem foi boa e o conteúdo foi } \\
\text { interessante. } \\
\text {... a matéria era difícil... }\end{array}$ \\
\hline & $\begin{array}{l}\text {...aprendemos que com nossos próprios conceitos podemos montar um } \\
\text { mapa... foi uma maneira simples, objetiva e direta para aprendermos melhor... }\end{array}$ \\
\hline & $\begin{array}{l}\text {.... o trabalho em grupo ajudou muito pois consegui aprender com mais } \\
\text { facilidade... as aulas eram completas e bem explicadas... com o grupo ficou mais } \\
\text { fácil aprender... }\end{array}$ \\
\hline
\end{tabular}

Com base na tabela 4 pode-se concluir que os alunos consideraram como aspectos positivos: a diversidade de metodologia, os trabalhos em grupo, a consideração de seus conhecimentos e a sua autonomia no processo da aprendizagem. O ponto negativo: conteúdo difícil.

A questão 6, foi apresentada de duas maneiras: 1a) $\mathrm{Na}$ aula, calculamos a energia total do sistema átomo de hidrogênio e encontramos a seguinte equação: E_n=-13,54/n^2 eV (elétron-Volt). (a) Qual grandeza física representada por En ? (b) Calcule os valores dos quatro primeiros níveis de energia do átomo de hidrogênio. (c) Represente o diagrama dos níveis de energia que você calculou em (b).; 2a) $\mathrm{Na}$ aula, calculamos o raio das órbitas do átomo de hidrogênio e encontramos a seguinte equação: $R n=5,31 \mathrm{n} 2$ (x 10-11metros). (a) Qual a grandeza física que é representada por $\mathrm{Rn}$ ? (b) Calcule os valores dos quatro primeiros raios níveis de energia do átomo de hidrogênio. (c) Represente na forma de figura o átomo de hidrogênio e suas 4 órbitas calculadas em (b). Na avaliação da questão 6 considerou-se que, 10 alunos responderam a questão corretamente, ver Figura 3(a); 4 alunos acetaram 2/3 da questão, ver Figura 3(b); 12 alunos acertaram 1/3 da questão; 5 responderam incorretamente, ver figura 3(c); e 24 alunos não responderam a questão. Assim, pode-se verificar como já era esperado, que a maior dificuldade do aluno está no uso da ferramenta matemática, e mais, que o aluno cria uma barreira, um pré-conceito que muitas vezes, nem tenta resolver a questão. 
I// RBECT

Revista Brasileira de Ensino
de Ciência e Tecnologia

Figura 3 - Respostas da questão 6.

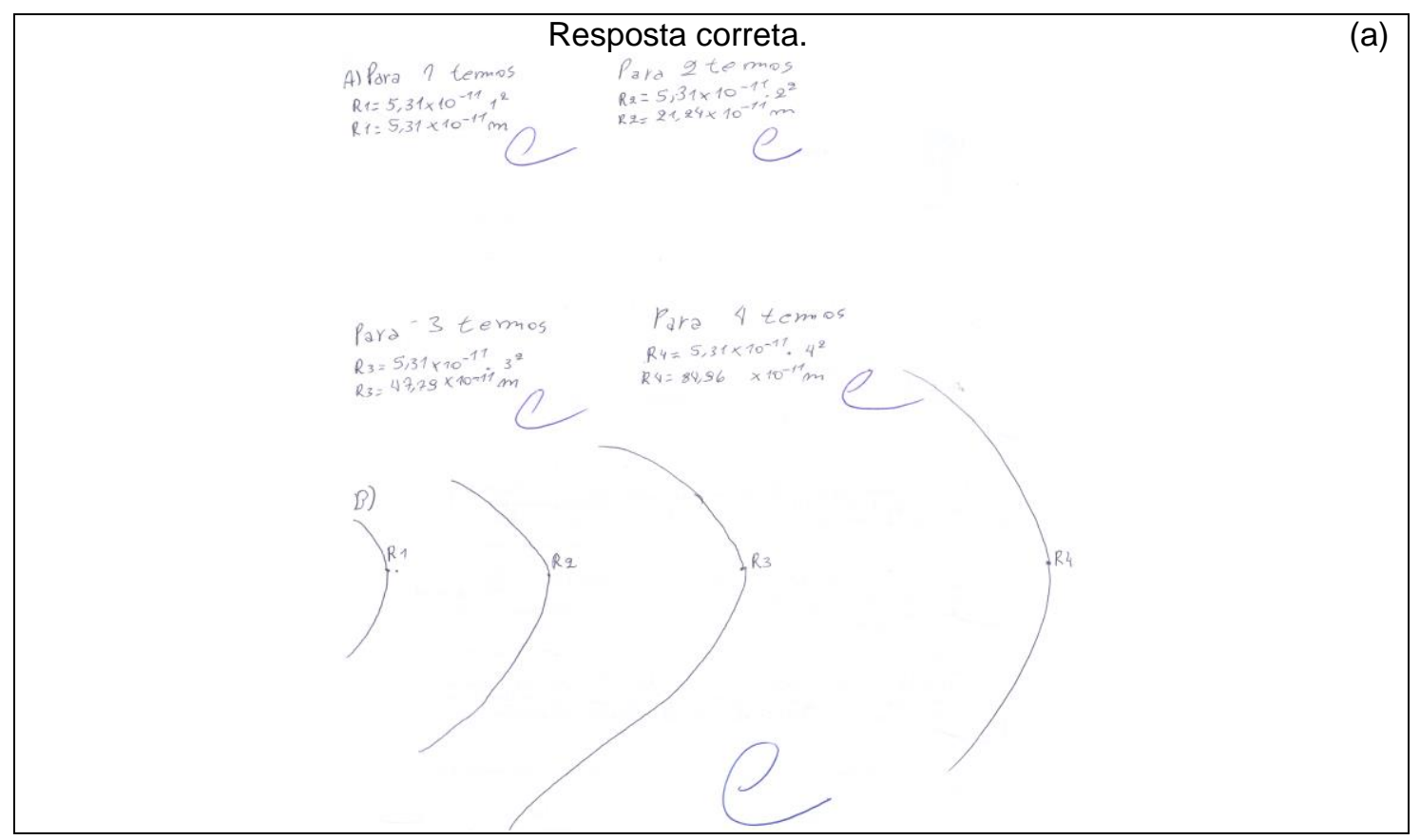

Página | 17

R. bras. Ens. Ci. Tecnol., Ponta Grossa, v. 9, n. 3, p. 1-24, mai./ago. 2016. 


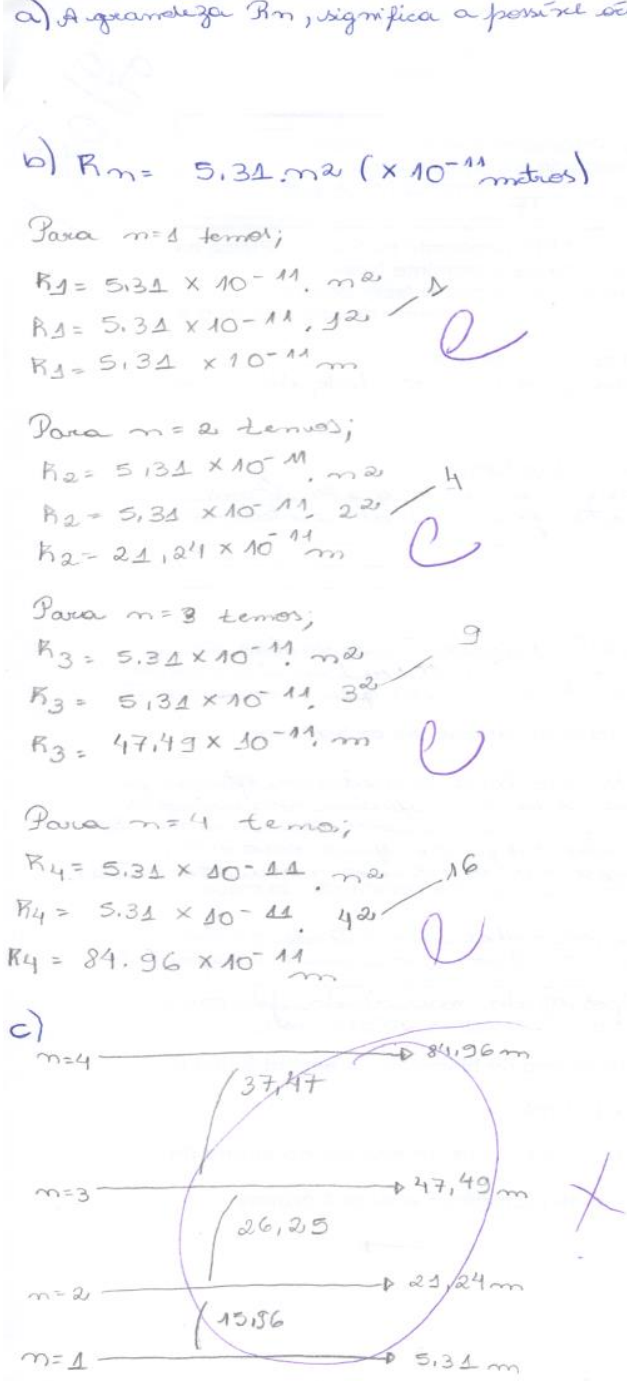

Resposta incorreta.

6. Na aula, calculamos o raio das órbitas do átomo de hidrogênio e encontramos a seguinte equaçăo:

$$
R_{n}=5,31 n^{2}\left(\times 10^{-11} \text { metros }\right)
$$

(a) Qual grandeza fisica representa o $R_{n}$ ? $D 2$ do Como da

(b) Calcule os valores dos quatro primeiros raios níveis de energia do átomo de

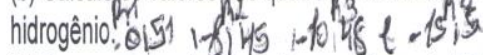

(c) Represente na forma de figura o átomo de hidrogênio e suas 4 órbitas calculadas em (b). .

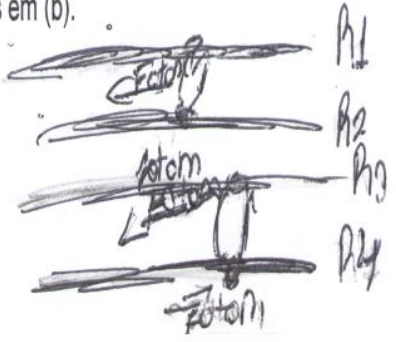


Na etapa VI da UEPS - Aula expositiva dialogada integradora final, a professora retoma os conceitos discutidos na UEPS com o processo de reconciliação integradora e diferenciação progressiva e, assim conclui a sua aplicação nas turmas do curso Técnico em Agropecuária. Observou-se que nessa atividade os alunos envolveram-se relatando como pensavam e como conseguiram "entender melhor" o conteúdo, a experiência positiva da construção dos mapas, de como foi bom trabalhar em grupo, também acrescentaram explicações sempre demostrando estarem motivados.

A avaliação da aprendizagem da UEPS é realizada na etapa VII. Nessa etapa avaliam-se os mapas livre e os mapas conceitual, a apresentação da aplicação do laser, a avaliação individual e a participação dos alunos para avaliar a UEPS, bem como comparam-se os resultados obtidos no estudo-piloto. Concluiu-se que os alunos do 1 o ano do Curso Técnico em Agropecuária obtiveram um bom aproveitamento, um ótimo envolvimento. Como já mencionado no perfil da turma, ao comparar os resultados da UEPS obtidos no estudo-piloto com as turmas do Curso Técnico em Informática de 2012 percebeu-se que os alunos apresentaram maiores dificuldades na aprendizagem, porém, gostaram mais das atividades em grupo e foram mais participativos nas interlocuções estabelecidas em sala de aula. Os alunos sentiram seus conhecimentos valorizados com o retorno imediato de todas as atividades desenvolvidas por eles. Não tem-se evidências conclusivas de aprendizagem significativa, mas certamente com as atividades desenvolvidas na UEPS conseguiu-se aumentar a predisposição do aluno para aprender nas aulas de Física.

Na etapa VIII avaliam-se as atividades propostas na UEPS. De acordo com a auto-avaliação dos alunos e com as anotações realizadas durante a aplicação da UEPS concluiu-se que ao acrescentar a questão 6 na avaliação somativa individual, os alunos tiveram maior dificuldade em realizá-la. Ratifica-se novamente, que a pesquisa qualitativa não tem como objetivo generalizar e a mudança de perfil de cada turma do Curso Técnico em Agropecuária as percepções se diferem, conforme relatado durante a análise dos resultados.

\section{Considerações Finais}

$\mathrm{Na}$ perspectiva ausubeliana, a Aprendizagem Significativa ocorre quando a nova informação ancora-se aos subsunçores do aprendiz. O principal desafio da pesquisadora seria fazer o público-alvo da pesquisa externalizar os subsunçores ou os conhecimentos prévios. Para isso foram elaboradas três atividades na UEPS: a construção do mapa livre, o questionário apresentado no passo II da UEPS, a leitura do texto "Os Fundamentos da Luz Laser" e destaque das palavras não compreendidas pelos participantes. Pois, o ponto de partida da pesquisa seria os conhecimentos prévios dos alunos. Com estas atividades propostas considera-se relevante: (1) o gosto dos alunos em realizar atividades em grupo, em trocar significados, ideias com seus colegas; (2) ao construir o mapa livre os alunos tentaram atribuir significados às palavras, explicaram entre elas e, negociaram com os colegas as suas posições; (3) a filmagem das explicações dos mapas livres foi uma ferramenta eficaz para detectar conhecimentos prévios; (4) no questionário realizado em grupo em grupo os alunos negociaram com os colegas 
especificamente sobre Laser; (b) mesmo relatando que tanto a Física Moderna quanto a Física Clássica estão presente no seu dia-a-dia, a maioria dos alunos exemplificou as implicações da Física com grandezas físicas da cinemática e dinâmica; (6) a leitura e destaque das palavras que os alunos não compreenderam o significados reflete: (a) o distanciamento entre o texto de divulgação científica e o vocabulário dos alunos envolvidos na pesquisa; (b) o distanciamento que o vocabulário do professor pode provocar entre professor e aluno; e (7) de modo geral, as três atividades propostas foram eficazes para que os alunos externalizassem seus conhecimentos prévios.

Com o uso de conhecimentos prévios foi formalizado os conhecimentos de Física envolvidos na UEPS Laser de Rubi. Nesta etapa da pesquisa observou-se que aulas expositivas e dialogadas foram participativas e de certa foram empolgantes, acredita-se que este fato deve-se a: (1) os alunos sentirem seus conhecimentos valorizados, pois o professor usava em suas explicações os conhecimentos prévios da turma, as respostas obtidas com o questionário, trechos das filmagens do mapa livre e retomava as palavras do texto que os alunos não compreenderam o significado; (2) a aula tornou-se dinâmica, pois os alunos participaram a todo momento, e sentiram-se capazes de contribuir com a aprendizagem do grupo; e (3) a utilização dos princípios da diferenciação progressiva e da reconciliação integradora na formalização dos conhecimentos.

Os alunos realizaram na sequência da UEPS a releitura do texto " Os Fundamentos da Luz Laser" e construíram um resumo ou esquema. Nessa atividade percebeu-se que: (1) ao reler os alunos compreenderam melhor o texto; (2) a releitura também foi utilizada com base no princípio da reconciliação integradora; (3) os alunos apresentaram em seus resumos ou esquemas as palavras que não faziam parte do seu vocabulário e as palavras que receberam para construir o mapa livre; e (4) utilizando a consideração (3) pode-se inferir que esta poderia ser uma evidência de aprendizagem significativa.

A atividade de pesquisa e apresentação de alguma aplicação do laser foi desenvolvida nas 3 turmas e percebeu-se que: um menor empenho comparado com as turmas do projeto-piloto, porém, todos os grupos apresentaram; a maioria dos temas dos trabalhos foi da área da medicina, realidade vivenciada pelos alunos, ou por algum conhecido, acrescentando relatado de casos de tratamento.

A avaliação somativa individual foi proposta para que a pesquisadora pudesse verificar a aprendizagem individual do público-alvo da pesquisa. Com base nos resultados apresentados, pode-se inferir que a maioria dos alunos conseguiram atingir $70 \%$ de aproveitamento na avaliação somativa individual e isto, pode ser considerada uma evidência de aprendizagem significativa.

Não há dúvidas que a atividade que os alunos mais gostaram de realizar foi a construção dos mapas. Durante a construção dos mapas livre foi detectado que: (a) os alunos não sabiam o significado da maioria das palavras; (b) os alunos pensavam que existia uma maneira correta para construí-los; (c) os alunos tinham a preocupação inicial se a atividade estava correta ou não; (d) os alunos adoraram a atividade; (e) os alunos passaram a atribuir suposições de significados às palavras; (f) os alunos tentaram explicar as palavras entre si. Durante a construção dos mapas conceituais os alunos: (a) perceberam que possuíam maior responsabilidade, pois já deveriam compreender os significados das palavras; (b) nenhum grupo acrescentou conectores e outras palavras que poderiam estar 
envolvidas com o tema Laser de Rubi; (c) atribuíram os significados de forma hierárquica de acordo com a formalização do conhecimento; e (d) perceberam que todas as palavras estavam conectadas.

Utilizando os critérios para a avaliação da UEPS considera-se que ela foi positiva, tanto como metodologia didática quanto em envolvimento, aproveitamento e aprendizagem. Assim, pode-se concluir que é possível inserir tópicos de Física Moderna e Contemporânea no primeiro ano do Ensino Médio e, mais, que a metodologia da UEPS foi decisiva na execução do problema de pesquisa. Conforme já mencionado, não tem-se evidências conclusivas de aprendizagem significativa, mas certamente com as atividades desenvolvidas com a UEPS Laser de Rubi conseguiu-se aumentar a predisposição dos alunos em aprender Física. 


\title{
Modern and Contemporary Physics in the first year of high school: Ruby Laser an example of Potentially Meaningful Teaching Units
}

\begin{abstract}
This article reports an experience of teaching topics of Modern and Contemporary Physics (MCP) in the 1st year of high school with the theme of Ruby Laser. The qualitative research methodology is primarily based on the Theory of Meaningful Learning Theory using some bias from Novak's, Theory of Education Gowin, Vergnaud's Theory of Conceptual Fields and Johnson - Laird's Mental models. The teaching methodology is the Potentially Meaningful Teaching Units (PMTU), and the specific issue of Ruby Laser. The PMTU was subject applied in two classes of the Technical Course on Computer Integrated in 2012 , at the Federal Institute of Education, Science and Technology Farroupilha, Campus Júlio de Castillos-RS. This paper refers to the continuing work to reapply PMTU in 2013 at the same educational institution, however the target audience of the study were students from three classes of the Technical Course in Integrated Farming.
\end{abstract}

KEYWORDS: Meaningful Learning, Laser, Physics Teaching and Potentially Meaningful Teaching Units. 


\section{REFERÊNCIAS}

Ausubel, D.P. Educational psychology - a cognitive view. New York: Holt, Rinehart and Winston, (1968).

Ausubel, D.P. The acquisition and retention of knowledge: a cognitive view. Dordrecht: Kluwer Academic Publishers, (2000).

Bagnato, V.S. Os Fundamentos da Luz Laser, Física na Escola, 2(2), 4-9, (2001).

Gowin,D.B. Educating. Ithaca, N.Y.: Cornell University Press, (1981).

Johson-Laird, P.N. Mental Models. Cambridge, MA: Harvard University Press, (1983).

Masini e Moreira, M.A. Aprendizagem significativa: condições para ocorrência e lacunas que levam a comprometimentos. São Paulo: Vetor, (2008).

Moreira, M. A. La Teoria de los Campos Conceptuales de Vergnaud, La enseñanza de lãs ciências y La investigación em el área. In: MOREIRA,M.A. (pp. 41-66). Porto Alegre. Instituto de Física da UFRGS, (2004).

Moreira, M.A. A teoria da aprendizagem significativa e sua implementação na sala de aula. Brasília: Editora da UnB, (2006).

Moreira, M.A., Veit, E. Ensino Superior: bases teóricas e metodológicas. São Paulo: E.P.U., (2010).

Moreira, M.A. Unidade de enseñanza potencialmente significativas UEPS (Potentially Meaningful Teaching Units - PMTU). Meaningful Learning Review, 1(2), 43-63, (2011).

Novak, J.D. Aprender criar e utilizar o conhecimento. Plátano Edições Técnicas, Lisboa, (2000).

Palandi, J.; Figueiredo, D.B.; Denardin, J.C. e Magnago, P.R. Física Moderna - GEFUFSM, Grupo de Ensino de Física, Universidade Federal de Santa Maria, (2010). 
Paulo,I. J. C. de. A Aprendizagem Significativa Crítica de Conceitos da Mecânica Quântica Segundo a Interpretação de Copenhagen e o Problema da Diversidade de Propostas de Inserção da Física Moderna e Contemporânea no Ensino Médio, Tese (Doutorado em Ciências) - Programa Internacional de Doctorado, Ensenanza de lãs Ciencias, Departamento de Didácticas Específicas. Universidade de Burgos, Burgos, España, (2006).

Pereira, A. P.; Ostermann, F. Sobre o ensino de Física Moderna e Contemporânea: uma revisão da produção acadêmica recente. Investigações em Ensino de Ciências, 14(3), 393-420, (2009).

Schittler, D; Moreira, M. A. Laser de rubi: uma abordagem baseada em unidades de ensino potencialmente significativas (UEPS). Latin - American Journal of Physics Education, v. 8, p. 263-273, 2014.

Soares, S. Um curso de Mecânica Quântica para professores de Física do Ensino Médio. Dissertação (Mestrado profissionalizante). Programa de Mestrado Profissionalizante, Programa de Pós-Graduação em Ensino de Física. Universidade Federal do Rio Grande do Sul, Porto Alegre, (2009).

Valadares, E.C. e Moreira, M.A. Aprendizagem Significativa: sua formação e implementação. Coimbra: Edições Almedina, (2009).

Vergnaud, G. La theórie dês champs conceptuels - Récherches em Didactique dês Mathématiques, 10(23), 133-170, (1990).

Recebido: 06 nov. 2014

Aprovado: 14 abri. 2016.

DOI: $10.3895 /$ rbect.v9n3.2407

Como citar: SCHITTLER, D : MOREIRA, M. A. É possível ensinar Física Moderna e Contemporânea no

primeiro ano do Ensino Médio? Como? Uma UEPS de LASER DE RUBI como exemplo. Revista Brasileira de

Ensino de Ciência e Tecnologia, v. 9, n. 3, 2016. Disponível em:

<https://periodicos.utfpr.edu.br/rbect/article/view/2407>. Acesso em: xxx.

Correspondência:

Direito autoral: Este artigo está licenciado sob os termos da Licença Creative Commons-Atribuição 4.0

Internacional. 